\title{
Editorial
}

\section{Texas Heart Institute Medal and the Ray C. Fish Award for Scientific Achievement in Cardiovascular Diseases}

$\mathbf{R}$ ay C. Fish (1902-1962) was a leading figure in Houston's natural gas industry and a philanthropist. He believed in the American dream of "opportunity for success." The Ray C. Fish Foundation was established so that others might be encouraged to broaden man's self-knowledge and to keep the American dream alive. After its founder's death from heart disease, the Fish Foundation granted $\$ 5$ million to make the Texas Heart Institute a reality. For this reason, the Institute's highest professional award is given in honor of this extraordinary man. The award recognizes those whose innovations have made significant contributions to cardiovascular medicine and surgery.

The first Texas Heart Institute Medal and Ray C. Fish Award for Scientific Achievement in Cardiovascular Diseases were presented in 1972 to Dr. Norman Shumway.

Since 1972, 35 other highly deserving recipients have been so honored by the Institute. The complete roll of recipients appears on the next page.

\section{Delos M. Cosgrove, MD}

Dr. Delos (Toby) Cosgrove is president and chief executive officer of the Cleveland Clinic. He heads a $\$ 6$ billion healthcare system that comprises Cleveland Clinic, 8 community hospitals, 16 family health and surgery centers, Cleveland Clinic Florida, Lou Ruvo Center for Brain Health (Las Vegas), Cleveland Clinic Toronto, and Cleveland Clinic Abu Dhabi.

Dr. Cosgrove received his medical degree from the University of Virginia School of Medicine and completed training at Massachusetts General Hospital and at Brook General Hospital in London. He earned his undergraduate degree from Williams College in Williamstown, Massachusetts. In 1967, he was a surgeon in the U.S. Air Force, serving in Da Nang, Vietnam. He was awarded the Bronze Star and Republic of Vietnam Commendation Medal.

Dr. Cosgrove joined the Cleveland Clinic in 1975 and was named Chairman of the Department of Thoracic and Cardiovascular Surgery in 1989. He performed more than 22,000 operations and earned international recognition in cardiac valve surgery before his retirement in 2006. He holds 30 patents for medical innovations.

He has received numerous awards and is ranked among Modern Healthcare's "100 most powerful people in healthcare" and "most powerful physician executives." His book, The Cleveland Clinic Way, was published by McGraw-Hill Education in 2014. 


\section{ROLL OF RECIPIENTS}

of the Texas Heart Institute Medal and the Ray C. Fish Award

for Scientific Achievement in Cardiovascular Diseases

1972

Norman E. Shumway

Cardiovascular Surgery (Heart

Transplantation)

1973 F. Mason Sones, Jr.

Cardiology (Coronary

Angiography)

1974 Eugene E. Braunwald

Physiology (Myocardial Preservation)

1975 Willem J. Kolff

Cardiovascular Surgery

(Artificial Organs)

1976 Harvey Feigenbaum

Cardiology (Echocardiography)

1977 John W. Kirklin

Cardiovascular Surgery (Heart-Lung

Machines)

1978 Bernard Lown

Cardiology (Cardiac Arrhythmias)

1979 John J. Gallagher and William C. Sealy

(co-recipients)

Cardiology and Cardiovascular Surgery

(Surgery for Pre-Excitation)

1980 W. Proctor Harvey

Cardiology (Clinical Practice and Teaching)

$1981 \quad$ Paul M. Zoll

Cardiology (Pacemaking)

1983 Andreas R. Grüntzig

Cardiology (Percutaneous Transluminal

Coronary Angioplasty)

1984 Hein J.J. Wellens and Douglas P. Zipes

(co-recipients)

Cardiology (Diagnosis and Management

of Pediatric Cardiac Arrhythmias)

1985 Denton A. Cooley

Cardiovascular Surgery (Surgery for

Congenital Heart Disease, Aneurysms

of the Aorta, and Implantation of the

Artificial Heart)

1986 William J. Rashkind

Pediatric Cardiology (Nonsurgical Treatment of

Congenital Heart Disease)

1987 Dwight E. Harken

Cardiovascular Surgery (Intracardiac Surgery)

$1988 \quad$ J. Willis Hurst

Cardiology (Writing and Teaching)

1989 Robert J. Hall

Cardiology (Clinical Practice and Teaching)

1990 Sol Sherry

Cardiology (Thrombolytic Therapy)

1992 Arthur S. Keats

Cardiovascular Anesthesiology

1997
Aldo R. Castañeda

Pediatric Cardiovascular Surgery
1997 Julio C. Palmaz

Radiology (Endovascular Stents)

1998 Magdi Yacoub

Cardiovascular Surgery (Heart-Lung

Transplantation)

1999 Thomas J. Fogarty

Cardiovascular Surgery (Medical and

Surgical Devices)

2004 James L. Cox

Cardiovascular Surgery (Surgery for

Atrial Fibrillation)

2004 Stephen Westaby

Cardiovascular Surgery (First Clinical Trial of

Axial-Flow Devices for Destination Therapy

and Significant Contributions to the Surgical

Literature)

2007 Charles E. Mullins

Pediatric Cardiology (Teaching and Pioneering

Work in Interventional Techniques for Congenital

Heart Disease)

2008 O.H. Frazier

Cardiovascular Surgery (Heart Transplantation and Research and Development of the Left

Ventricular Assist Device)

2009

James T. Willerson

Cardiology (Pioneering Work in Unstable

Atherosclerotic Plaques, Acute Coronary

Syndromes, and Cardiac Stem Cells)

2010 Charles D. Fraser, Jr.

Cardiovascular Surgery (Development of a Program Known for Its Effectiveness in Correcting Congenital Cardiovascular Disease in Children)

2011 Patrick W. Serruys

Interventional Cardiology (Major Contributions to Interventional Cardiology, Including Those to the Development of Both Bare-Metal and DrugEluting Stents)

2012 George J. Reul

Cardiac and Vascular Surgery (Development of an Accredited Vascular Lab at SLEH; Leader in Quality Measures)

2013 Alain G. Cribier

Interventional Cardiology (First Balloon Dilation of Aortic Valve for Calcific Aortic Stenosis, 1985;

and First Implantation of a Prosthetic Aortic Valve via Cardiac Catheterization, 2002)

2014 Terence English

Cardiovascular Surgery (Establishing Heart

Transplantation Program in England)

2015 Delos M. Cosgrove

Cardiovascular Surgery (Significant Contribu-

tions to Cardiac Valve Repair) 